\title{
EFFICIENCY OF THE MODEL FOR FORMATION OF PROFESSIONAL- PEDAGOGICAL COMPETENCE FOR SPORTS ANIMATION ACTIVITY
}

\author{
Donka Zheleva-Terzieva ${ }^{1}$
}

\begin{abstract}
:
Introduction: Thise article discusses the effectiveness of an educational model for students and postgraduates in acquiring vocational pedagogical competence for sports and animation activities in an educational environment.

Study Objective: The authors are based on the Kirkpatrick assessment model. Presented are results that shall establish the degree of effectiveness of applications at the Pedagogical Faculty of Trakia University, Stara Zagora of the competency model of three indicators - degree of satisfaction from the training program, degree of acquiring of competence and learning outcomes.
\end{abstract}

Methods: The methods of pedagogical research used are: questionnaire, didactic test, pedagogical observation, expert evaluation.

Results: The results prove the effectiveness of the developed didactical model.

UDC Classification: 378, DOI: https://doi.org/10.12955/pss.v1.85

Keywords: sports animation, pedagogical model, model performance.

\section{Introduction}

In recent decades, after the transition from an industrial to a post-industrial society, dynamic social and economic changes, scientific and technical and information achievements, there is a discrepancy in today's society between the level of physical activity necessary to maintain good health and the actual level of movements performed in everyday life. As a consequence of this, a number of negative phenomena related to the state of health not only of adults but also of the rising generation are observed. Against this background, a higher school is called upon to respond appropriately to the new challenges. The education of pedagogical professionals is valuable because educators are those who train, direct and educate future generations. The Educational environment is acting as a source of diverse cultural experience, the learning of which is largely determined by the competent use of the complex of pedagogical resources (Georgieva, 2019; Valchev \& Tsonkova, 2018). In relation to the increased requirements, it becomes a key thesis for the high efficiency of the training of kindergarten and primary teachers as recognised specialists, possessing the necessary professional competence, exhibiting flexibility and responsibility for the results of their activities and striving for selfimprovement (Delchev, 2017).

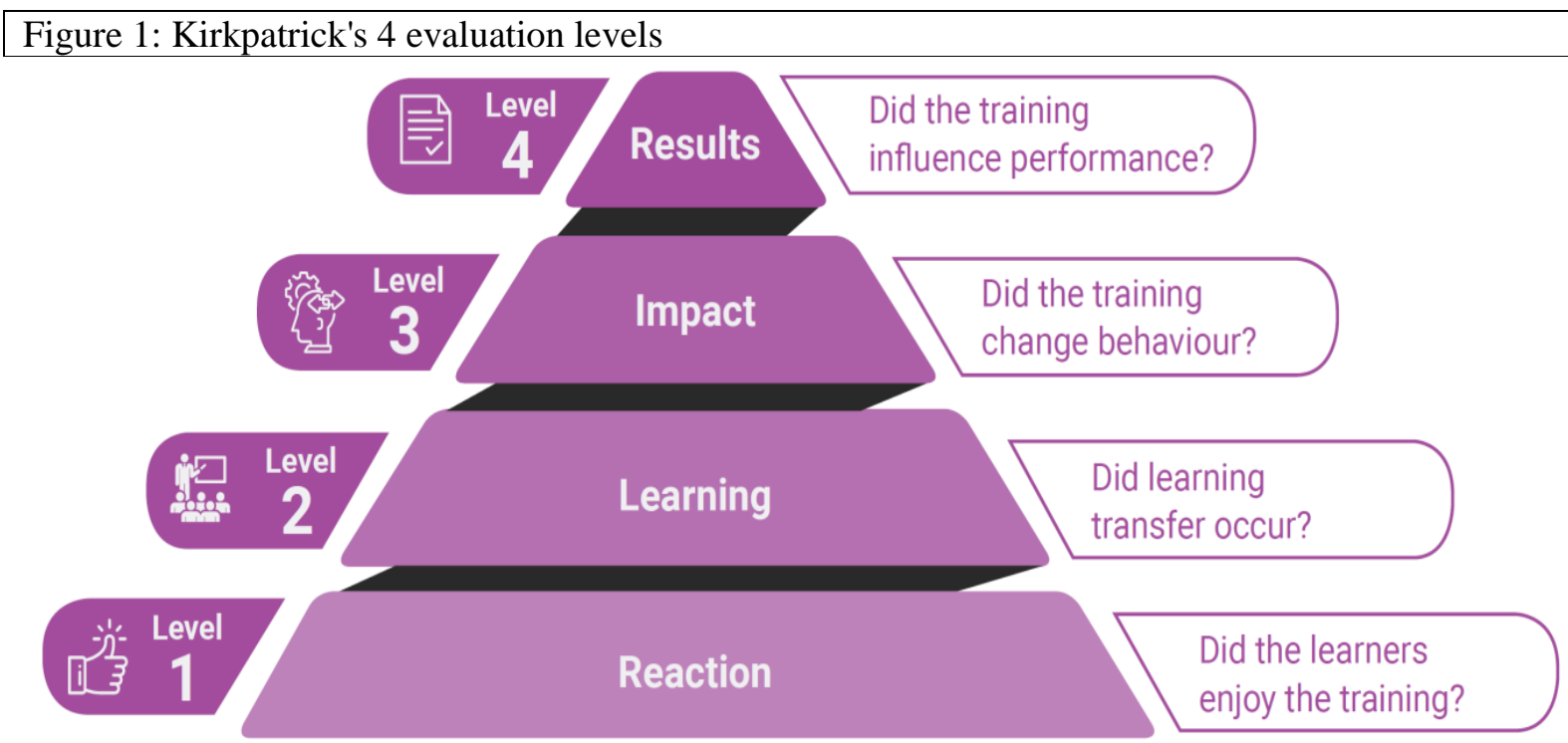

Source: Bretz (2018)

In response to the problems considered, related to the insufficient physical activity of adolescents and in search of effective forms of counteraction against hypodynamia, an author's model for the formation

\footnotetext{
${ }^{1}$ Trakia University, Faculty of Education, donkazeleva@gmail.com
} 
of professional-pedagogical competence for the realization of sports animation activity in an educational environment was tested (Zheleva-Terzieva, 2020).

\section{Study objective}

In order to develop the didactic model with regard to the methodology of the training, a combination of techniques, methods, instruments and pedagogical techniques for appropriate organizing and realization of the training is used. To determine the effectiveness of the developed competency model, we are based on the Kirkpatrick assessment model (D. Kirkpatrick \& W. Kirkpatrick, 2016), which consists of four levels presented in Figure 1, borrowed from F. Bretz (Bretz, 2018).

The changes that are expected to occur on the first two levels refer to the learners, and to the second two to the organization in which the trained people already work and the contingent they influence.

Performance shows the relationship between objectives and results achieved. Indicators for determining the effectiveness of competency model applied according to V. Georgiev are (Georgiev, 2011):

- Students' satisfaction with the training (curriculum) program;

- Degree of formation of competence for realization of sports and animation activities (knowledge, skills, relations);

- $\quad$ Results of the training.

\section{Results}

The first indicator gives data of the conducted study to establish the degree of satisfaction of the educational program through a standardized written questionnaire. The respondents were 129 students from the Faculty of Pedagogy, Trakia University, from specialty "Preschool and Primary School Pedagogy" first and second course of the EQD "Bachelor", held after the end of the summer semester of the academic year 2017/2018. The questions in the questionnaire were two with scaled answers (Bizhkov \& Kraevski, 2007) and concerned the satisfaction of the persons surveyed with the quality of the information for acquiring knowledge and the practical exercises for mastering the skills for the realization of sports animation activities. The degree of satisfaction is expressed by the number scale of 5 (highest grade) to 1 (lowest grade). The results are presented in Figure 2.

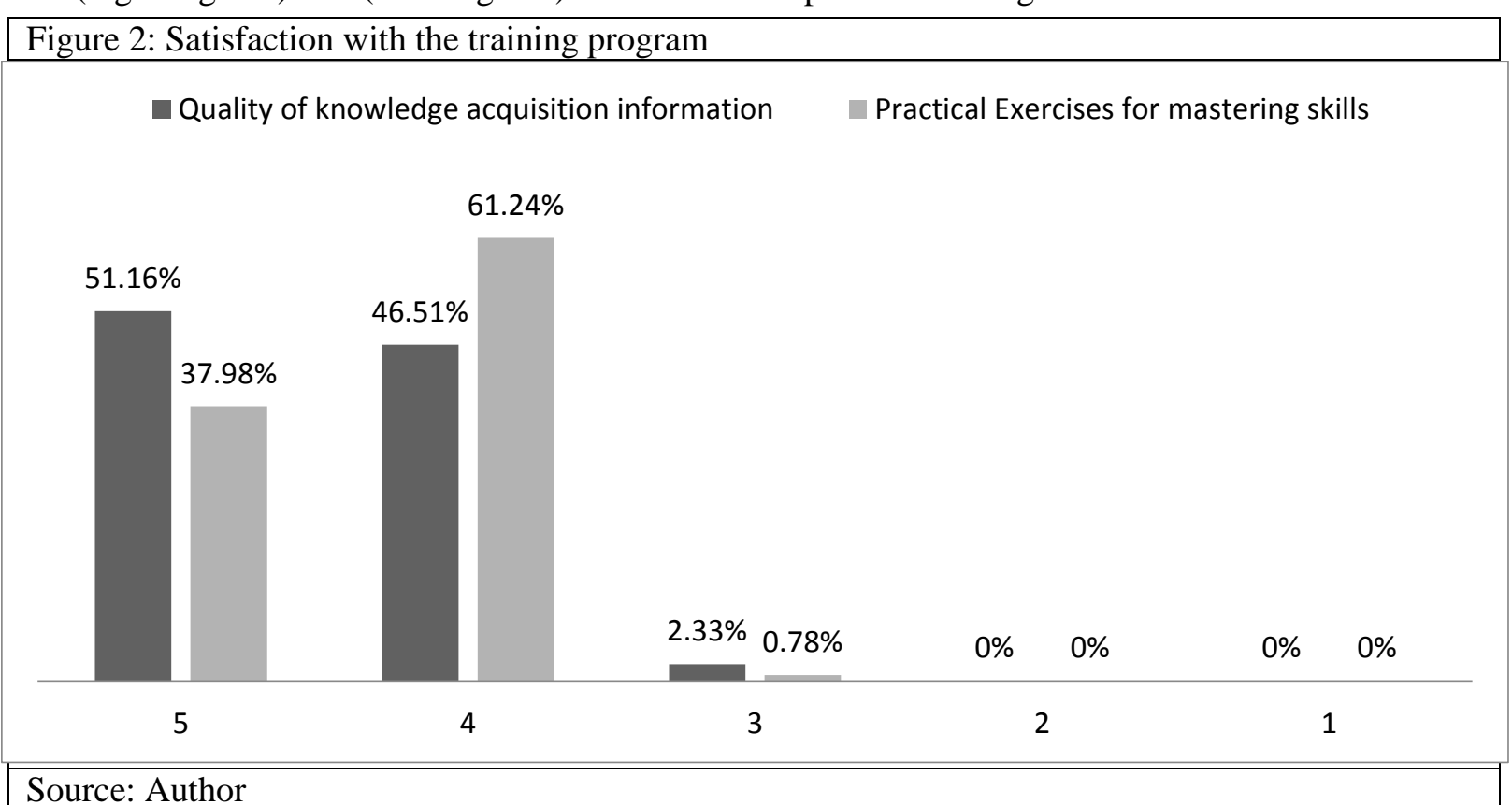

Source: Author

The data show a high degree of satisfaction, both from information about acquiring knowledge, and from the skills exercises, as a component part of the professional-pedagogical competence for sports and animation activities.

In the second question, in terms of the effectiveness of the model created, we present data from a statistical analysis of the results obtained from a didactic test carried out for the assessment of the acquired knowledge, a pedagogical monitoring of mastered skills and relationships during and after 
the training of the course and the subsequent expert assessment in reflecting the results of the monitoring.

A didactic final test involving a total of 18 tasks, divided into three groups, was used to check the extent of the students' knowledge of the school discipline:

- Group I -15 tasks of a structured close-end type (Bizhkov \& Kraevski, 2007) with 4 variants of response, one of which is correct;

- Group II and III include a total of three tasks where the degree of assessment of knowledge is through a three-tier scale: Does not know, Knows to some extent, Knows: 1 referencing task; 1 short answer task and 1 task to complete (Rapp, 1975).

A statistical analysis of the characteristics of the test-objectivity, reliability and validity was performed and the characteristics of the tasks-difficulty, discriminatory strength and analysis of the distractors (in the group I tasks) as the results showed the high quality of the final test. Results obtained from the application of the test on the same learners are presented in table 1 (total number of 129 students - 65 of I course and 64 of the II course).

\begin{tabular}{|c|c|c|c|}
\hline \multicolumn{5}{|c|}{ Table 1: Number of correct replies to task Group I and number of solved tasks from Group II and III } \\
\hline Task & I course & II course & Total \\
\hline 1 & 52 & 49 & 101 \\
\hline 2 & 47 & 46 & 93 \\
\hline 3 & 50 & 49 & 99 \\
\hline 4 & 46 & 51 & 97 \\
\hline 5 & 45 & 51 & 96 \\
\hline 6 & 44 & 51 & 95 \\
\hline 7 & 43 & 58 & 101 \\
\hline 8 & 47 & 57 & 104 \\
\hline 9 & 48 & 55 & 103 \\
\hline 10 & 44 & 57 & 101 \\
\hline 11 & 43 & 46 & 89 \\
\hline 12 & 45 & 48 & 93 \\
\hline 13 & 45 & 52 & 97 \\
\hline 14 & 48 & 42 & 90 \\
\hline 15 & 47 & 48 & 95 \\
\hline 16 & 43 & 36 & 79 \\
\hline 17 & 36 & 42 & 78 \\
\hline 18 & 19 & 36 & 55 \\
\hline Total & 792 & 874 & 1666 \\
\hline Relative share, $\%$ & 67.69 & 75.87 & 71.75 \\
\hline
\end{tabular}

Source: Author

The data show a relatively high degree of acquired knowledge, expressed through a high percentage of the relative share of the said correct answers $(71.75 \%)$.

The level of mastered skills (13 in number, manifested by the solving of 2 written tasks, implementation of the practical assignment and solving of 2 cases) and the developed relations (personal qualities responsibility, purposefulness and discipline) are assessed by pedagogical observation and expert assessment of the three-step scales: Not capable of, Is capable to a certain degree, Is capable of skills (the results of the study are presented in the table 2) and Low, Medium, High degree of relations (the results of the study are presented in the table 3 ).

The results obtained show a relatively high degree of mastered skills, expressed through a high percentage of the relative share of the highest skill level IS CAPABLE $(65.43 \%)$.

The results obtained also show a high degree of personal qualities (relationships) expressed by a high percentage of the relative proportion of the degree of manifestation HIGH $(64.86 \%)$.

In relation to the third indicator, we present data from a survey conducted with 52 persons who have undergone the course of study, which, at the time of the study (January 2020), are already working in their specialty. 52 women aged 22 to 45 were interviewed. The number of teachers was 37 , and the educators-15. Of the persons included in the survey, 24 worked with a contingent of preschool children (3-6 years old) and 28-with pupils from elementary school age (7-10 years old). The 
questions in the questionnaire were 4 in number: Two with alternative answers and two with closedended answers menu.

- 1st question: "Have you performed sports-animation activities before the training?"

- 2nd question: "Do you have sports-animated activities after the training? "

The results obtained from the answers to the first two questions are presented in Figure 3.

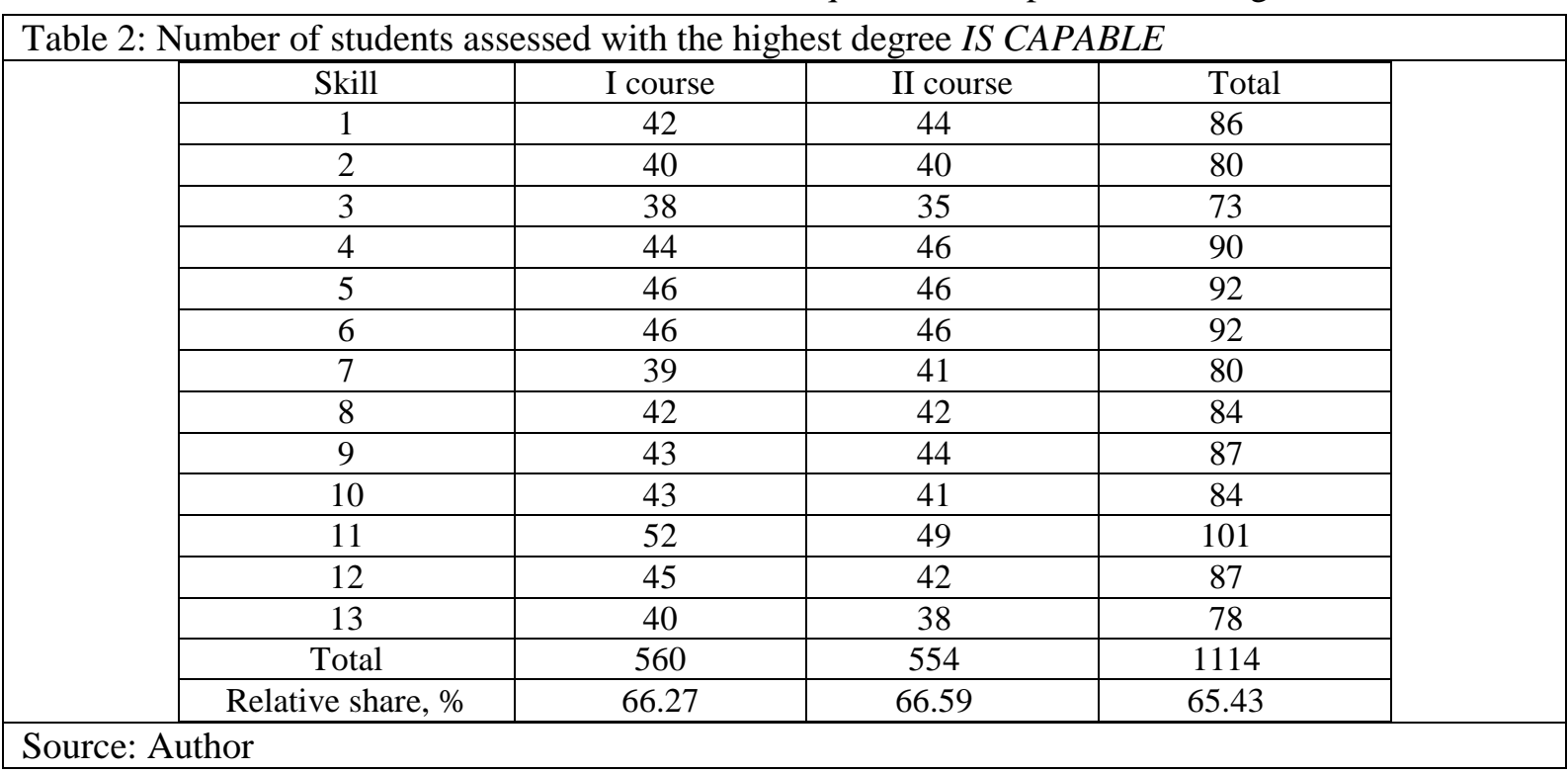

Table 3: Number of students evaluated with a HIGH DEGREE of personal qualities

\begin{tabular}{|c|c|c|c|}
\hline Relation & I course & II course & Total \\
\hline Responsibility & 39 & 36 & 75 \\
\hline Purposefulness & 41 & 39 & 80 \\
\hline Discipline & 48 & 48 & 96 \\
\hline Total & 128 & 123 & 251 \\
\hline Relative share, $\%$ & 65.64 & 64.06 & 64.86 \\
\hline
\end{tabular}

Source: Author

Figure 3: Answers to questions with alternative answers

No $\square$ Yes

$78.85 \%$

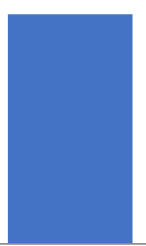

1st question
$48.08 \% \quad 51.92 \%$

$21.15 \%$

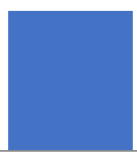

2nd question

Source: Author

The results show that the number of educators engaged in sports-animation activities after the training has significantly increased.

- 3rd question: "What is the weekly frequency of sports and animation activities before the training?"

- 4th question: "What is the weekly frequency of sport-animation activities after training?"

The results obtained from the answers to the questions with closed-ended answers menu are presented in Figure 4. 


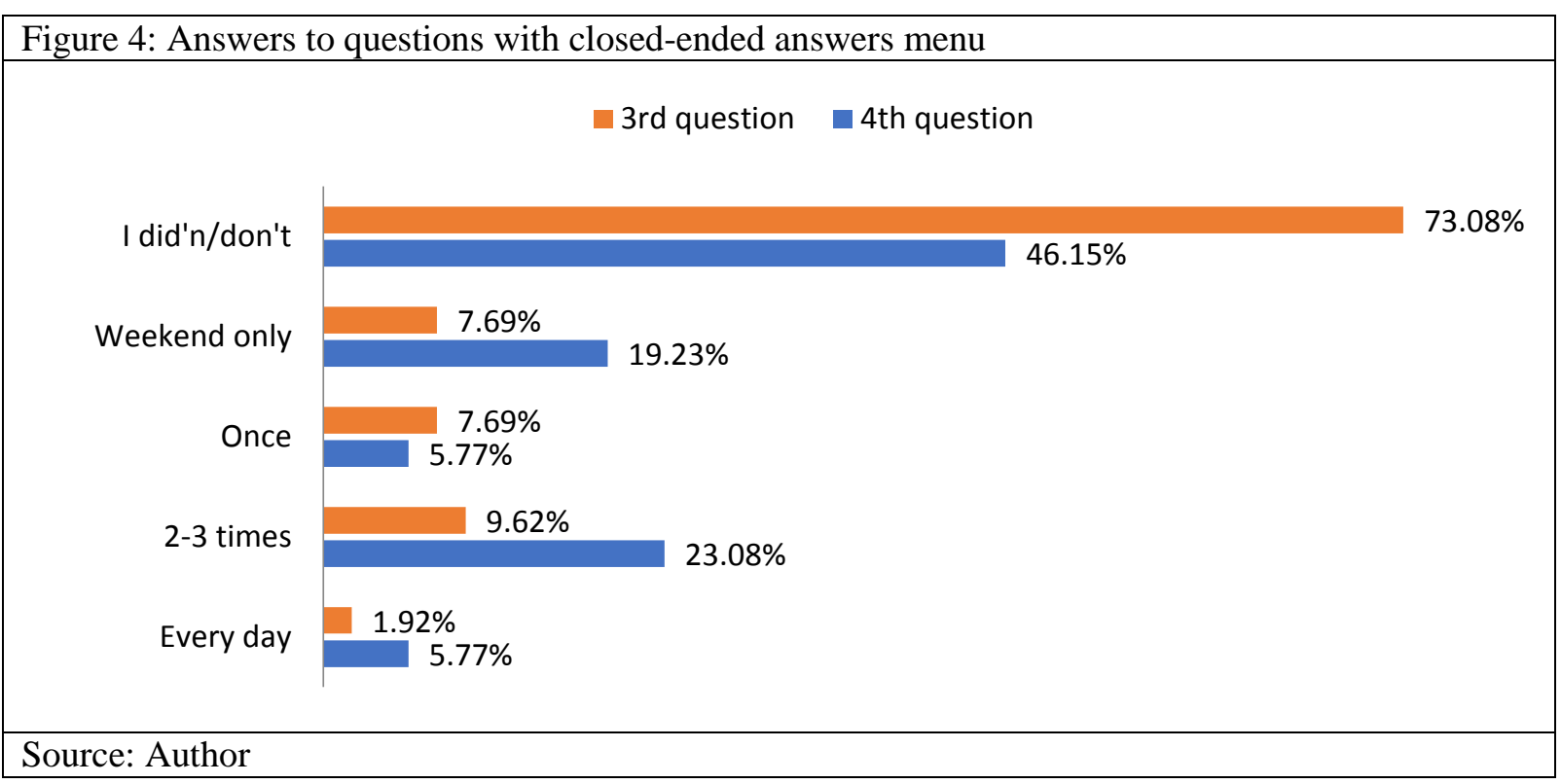

The results show that the frequency of activities in the weekly cycle has also increased.

\section{Conclusion}

As a result of the testing of the model, it can be stated that the majority of the learners solve the assigned tasks adequately and demonstrate initiative, responsibility, discipline, purposefulness, are able to plan, organize and conduct sports-animated activities, analyse and correct the results of their activities. Almost all respondents indicated a high degree of satisfaction with the training course "Sports animation in an educational environment" and the majority of them actively applied in practice the acquired competence.

The overall results of the study make it possible to confirm the effectiveness of the developed didactic model, which implies that this leads to a qualitative building of the necessary level of professional competence for the realization of sports and animation activities for students and postgraduates from pedagogical specialties.

\section{References}

Bizhkov, G., Kraevski, V. (2007). Methodology and methods of pedagogical research. Sofia: University Publishing House "St. Kliment Ohridski".

Bretz, F. (2018). How to Master Kirkpatrick model of training evaluation. Retrieved from https://kodosurvey.com/blog/howmaster-kirkpatrick-model-training-evaluation

Delchev, M. (2017). A model of training content for the acquisition of complex cartographic literacy in the students of the specialty "Elementary School Pedagogy", E-magazine "Pedagogical Forum", 4. Retrieved from https://www.dipkuszforum.net

Georgieva, D. (2019). Professional-personal readiness of the teachers as social-psychological resource for development of social adaptation of children with Down syndrome, Pedagogy, 91 (5), 626-641.

Georgiev, V. (2011). Methods to take into account the effectiveness of introducing the competency model. Retrieved from www.competencemap.bg

Kirkpatrick, J. D., W. K. Kirkpatrick (2016). Four Levels of Traning Evaluation. Alexandria: ATD Press.

Valchev, G., Tsonkova, V. (2018). Inclusive education - Evolution of Educational Desegregation, Strategies and cooperation for sustainable education policies, Educational Forum, DIPKU, St. Zagora, 471-477.

Zheleva-Terzieva, D. (2020). Model for formation of professional-pedagogical competence for sports-animation activity. Emagazine "Pedagogical Forum", 1. Retrieved from https://www.dipkusz-forum.net. 